\title{
As dificuldades de construção de uma sociedade democrática no Brasil: os elementos extrapolíticos nas análises dos processos sociais em Fernando de Azevedo
}

\author{
MARIA JOSÉ DE REZENDE \\ Doutora em Sociologia - USP \\ Professora da Universidade Estadual de Londrina - UEL \\ wld@rantac.net
}

\begin{abstract}
Resumo
As discussões de Fernando de Azevedo a respeito da vida política brasileira, desde os primórdios da formação social do país, serão privilegiadas neste artigo. Ele construiu uma das mais férteis reflexões no campo da cultura política ao buscar historicamente as dificuldades de constituição de uma sociedade democrática e, ao mesmo tempo, ao empenhar-se em apontar os caminhos que deveriam ser seguidos para alcançá-la. Demonstrando que as mudanças substanciais somente são possíveis quando ocorrem modificações das mentalidades que lhes orientam, ele contribuiu para a sedimentação, no âmbito da sociologia, das investigações que valorizavam os elementos extrapolíticos nas análises dos processos sociais.
\end{abstract}

Palavras-chaves: política; sociedade; mudança; cultura; diferenciação.

\section{Introdução}

\begin{abstract}
o buscar compreender a forma de domínio no Brasil, em vista A tanto das origens quanto da evolução do processo social, Fernando de Azevedo (1894-1974) ${ }^{1}$ sedimentava, no país, uma abordagem sociológica da política. Suas obras - A cultura brasileira (1996), Canaviais e engenhos na vida política do Brasil (1958) e A cidade e o campo na civilização industrial e outros ensaios (1962) - demonstravam as múltiplas complexidades das relações definidoras da economia, da política e da cultura. Naquela segunda obra, por exemplo, ele partia do pressuposto de que as interações constituidoras do patriarcalismo só podiam ser desvendadas por meio de seus conteúdos sociais, os quais devem ser entendidos como valores, crenças, tradições e sentimentos que amalgamaram os contatos entre os diversos grupos.
\end{abstract}

1 Fernando de Azevedo foi um dos principais cientistas sociais brasileiros. Atuou como professor de Sociologia da Universidade de São Paulo e em outros cargos públicos na área de Educação. Entre 1927 e 1930 dirigiu a reforma da instrução pública do Rio de Janeiro. Foi diretor da Instrução Pública do Estado de São Paulo, Secretário de Educação do Estado de São Paulo e Presidente da Sociedade Brasileira de Sociologia. 
A organização social brasileira cristalizou, durante os séculos, formas de conflito, de exclusão, de trabalho, de hierarquização etc., que iam definindo modos de ação e de interesses políticos quase que petrificados ao longo do tempo. Em razão disso, o fim do trabalho escravo, a implementação do trabalho livre, a urbanização, a industrialização, as proclamações da independência e da república, se constituíam fatores de diferenciação e de evolução social ${ }^{2}$ (Azevedo, 1956) que atingiram em maior grau as esferas econômica e social e em menor a esfera política.

Fernando de Azevedo buscava no interior da organização social e política brasileira os elementos indicadores de evolução dos indivíduos, dos grupos e das instituições sociais. Se, para ele, o progresso significava a constituição de uma classe dirigente voltada para o atendimento dos interesses coletivos e nacionais era necessário esmiuçar os contínuos bloqueios que foram minando sucessivamente a sedimentação de ações capazes de conduzir o país a diferenciações potencializadoras de mudanças políticas substantivas.

\section{A evolução política brasileira analisada à luz do processo social}

A obra Canaviais e engenhos na vida política do Brasil é reveladora da intenção do autor de fazer uma leitura da política brasileira à luz de um sistema de cultura e de economia que teria predominado durante três séculos, no mínimo. Ou seja, a colônia e o império teriam sido dois períodos sedimentadores de uma dualidade que permaneceu como o grande desafio da república brasileira: o locus da política estava em dois pólos basicamente, ou seja, no "poder central (...) e no mundo dos engenhos e, mais tarde, nas fazendas do café" (Azevedo, 1958, p. 14). Ele seguia a trilha deixada por Sérgio Buarque de Holanda que afirmava em Raízes do Brasil que "a partir de 1889, a casa de cada família de fazendeiros era uma verdadeira república privada" (Rezende, 1996, 1996a; Holanda, 1987).

O elemento político não era concebido por Fernando de Azevedo como qualidade e/ou tonalidade de um dado processo social. As perspectivas fundadas na necessidade de pinçar no interior da vida social o fator político e, portanto, isolá-lo e fixá-lo como material de análise acabavam por proceder a uma abordagem frouxa e pouco convincente.
Em sua visão, baseada numa análise sociológica da política, era possível

em organizações sociais, do tipo dominante em civilizações agrárias, como a do açúcar [...], surpreender com mais clareza as relações entre o político e a família, entre o político e o religioso, entre o gládio eclesiástico e a espada secular, e entre o poder político e o poder econômico, - essas duas coisas essenciais, tão intimamente ligadas à totalidade das atividades do grupo e à própria estrutura deste e não simplesmente a tal ou qual categoria dessas atividades. Como e porque as instituições domésticas, religiosas e econômicas se acham estreitamente associadas ao político, nesse regime social ligado ao sistema de unidade agrária de produção (monocultura), com base na escravidão; por qual processo e sob a pressão de que causas se operou a dissolução desses elementos; quais os resíduos que ficaram, na vida política, do regime patrimonialista e da concepção personalista do poder; como, no meio colonial, se desenvolveu a idéia de autonomia e de pátria, que se vem afirmar contra o próprio colonizador, e o papel que teve a assimilação de raças e de culturas, nesse processo de emancipação; as lutas de famílias, as relações entre as classes, os choques entre a cidade e o campo, entre a aristocracia rural e a burguesia urbana, são outros tantos problemas e fatos, de cuja análise se projetará uma luz viva não somente sobre as sociedades em questão mas sobre as próprias teorias que, sendo representações da realidade, devem modificar-se com os progressos da ciência e permanecem sujeitas à verificação e à crítica de novos fatos (Azevedo, 1958, p. 15).

Analisar sociologicamente a política significava, para Fernando de Azevedo, antes de mais nada, situar o homem e o grupo na paisagem social. Isso significava desvendar em que bases se definiram a organização social e econômica e o padrão de cultura que sedimentou uma dada mentalidade coletiva. O que não poderia ser feito se o cientista social se ativesse somente às grandes estruturas de propriedade e de domínio prevalecentes na época da civilização do açúcar. Era preciso esmiuçar o meio interno que formava esta sociedade, ou melhor, os "meios secundários que formaram as gerações, os sexos e os subgrupos sociais" (Azevedo, 1958, p. 17).

A coerção que dava sustentação ao padrão de domínio patriarcal e potencializava a sua natureza autoritária tem que ser buscada não somente na macro relação entre o senhor do engenho e o poder central, o senhor do engenho e a Igreja, o senhor de engenho e a instituição da escravidão, mas também na relação e a Durkheim $(1984 ; 1996 ; 1913)$. Em suas análises sobre a política brasileira, ele partia das teorias da diferenciação que foram desenvolvidas pelo evolucionismo sociológico no século XIX e XX. Ele supera, no entanto, a noção de diferenciação naturalista (Sztompka, 1998, p. 183; Timasheff, 1965; Goldthorpe, 1971; Levine, 1997) de Spencer ao se centrar nas teorias de Durkheim (1958-1917) "que recusava a tese do esquema unilinear de evolução que seria comum a todas as sociedades" (Cuche, 1995, p. 53). 
que o aristocrata rural estabelecia com os seus parentes e agregados, a qual se encontrava embebida de um sentimento de tolerância, obediência e resignação por parte daqueles últimos. Isso ajudou a potencializar a política de desmandos que se desenvolveu no Brasil desde os seus primórdios. A cristalização de uma mentalidade autoritária era, assim, uma das chaves mais importantes para compreender a forma e o conteúdo da política brasileira não somente na colônia e no império, mas também na república.

O desvendamento das (im)possibilidades de mudança social no Brasil teria que passar, então, pela análise dos diferentes aspectos do sistema de relações sociais. Ou seja, a relação entre os sexos no âmbito da família patriarcal, o papel da mulher, o papel dos filhos, a clausura imposta às filhas, a permissividade consentida aos homens, fossem eles de qualquer idade e/ou estado civil. O modo como os diversos grupos sociais vivenciavam os seus papéis e os reproduziam tem, para Fernando de Azevedo, importância capital na definição de uma cultura em que a família tem supremacia absoluta sobre o indivíduo. Nessas condições, "nas sociedades do tipo patriarcal, o que vale não é, porém, o indivíduo em si mesmo, mas a família (que) o enquadra" (Azevedo, 1958, p. 80).

A ação desses grupos secundários permitia compreender a natureza política e cultural da estrutura patriarcal. A sustentação das formas de produção, da concentração da riqueza e da propriedade, do status quo etc., não se fazia, porém, somente pela força e da coerção, mas também de um tipo de solidariedade que enlaçava os diversos grupos sociais. Nos moldes de Durkheim ele considerava que havia "em todas as sociedades uma consciência coletiva" (Durkheim, 1996), constituída das "representações, dos ideais, dos valores e dos sentimentos comuns" (Cuche, 1999, p. 57) que enlaçavam os indivíduos ${ }^{3}$. Fernando de Azevedo afirmava que tinha a intenção de "analisar os caracteres particulares que essa civilização (ibérica) tomou no interior do país, sob a pressão de fatores e de acordo com as condições diversas de nossa evolução histórica e social" (Azevedo, 1996, p. 38). Segundo ele,

os diferentes quadros geográficos e os variados grupos humanos formadores do território nacional apontavam para a necessidade de desenvolvimento de um projeto civilizacional que renovasse continuamente os principais traços culturais oriundos do encontro entre as culturas nativas latino-americanas e ibéricas. Nos moldes de Durkheim e de Mauss, Fernando de Azevedo recusava a tese de inferioridade cultural dos povos da América Latina. A constituição de um eixo civilizacional no continente era possível porque havia uma pluralidade de civilizações que se cruzaram e resultaram num padrão de organização social e de cultura singular, mas não inferior (Rezende, 2005, p. 176).

Fernando de Azevedo seguia os ensinamentos dos dois pensadores franceses que, segundo Cuche, se

esforçavam para propor uma concepção objetiva e não normativa da civilização que incluía a idéia da pluralidade das civilizações sem enfraquecer, com isso, a unidade do homem. Para Durkheim e Mauss (1913, p. 60-1), não havia dúvida de que a humanidade é uma, que todas as civilizações particulares contribuem para a civilização humana. Ele(s) não concebia(m) diferenças de natureza entre primitivos e civilizados (Cuche, 1999, p. 52).

Se, por um lado, essa abordagem durkheimiana fornecia subsídios plausíveis para explicar o vigor do patriarcalismo como uma forma de domínio que se alimentava de um conjunto de valores e de sentimentos, por outro, os ensinamentos do sociólogo francês conduziam a análise de Azevedo a dificuldades insolúveis, já que não era possível supor a existência de uma consciência coletiva comum a todos os indivíduos em uma sociedade escravocrata. Isso implicaria a pressuposição de que também os escravos possuíam valores e sentimentos comuns a todos os demais grupos sociais.

Fernando de Azevedo, ao ver-se diante desse dilema, tentava amenizar a aplicação da noção de consciência coletiva e, para isso, passava a traçar um percurso que, às vezes, se distanciava de Durkheim e se aproximava de Gilberto Freyre na busca de elementos que atestassem a constituição, graças à mestiçagem, de um processo social que tendia, segundo Azevedo, a operar uma espécie de expansão da consciência coletiva. Enlargueciam-se, assim, as dificuldades oriundas da junção de duas perspectivas teóricas inteiramente distintas. A análise de Freyre calcada no homem situacional, no indivíduo, não tinha como ser casada com a abordagem do sociólogo francês.

A perspectiva freyriana está muito distante da conceituação de sociedade proposta por Durkheim, aproximando-se inequivocamente do psicologismo de Tarde (1843-1904) e, principalmente, do intersubjetivismo de William Isaac Thomas (1863-1947). A Gilberto Freyre não interessa a redução idealista da 'consciência coletiva', de Durkheim, como não interessa a delimitação nominalista de fronteiras entre a sociologia, a psicologia e a biologia, fundamental, cabe repetir, na perspectiva durkheimiana (Vila Nova, 1995, p. 61).

A saída encontrada por Fernando de Azevedo foi considerar que a consciência coletiva mantenedora do padrão de organização e do padrão de domínio en- 
globava, de modo integral, os tipos sociais preponderantes na sociedade patrimonial, ou seja, aqueles que formavam as elites e os setores intermediários, mas não os escravos. O tipo principal, como o senhor de engenho, e os tipos secundários, como artífices, feitores, mestre de açúcar, oficiais mecânicos, banqueiros, administradores, mercadores, vaqueiros etc. compartilhavam de valores e de sentimentos comuns. A essencialidade deste tipo de organização social podia ser observada na maneira como a política nacional era atingida em cheio pela solidariedade social, que amalgamava tais grupos e seus interesses.

A dilatação da consciência coletiva tinha na mestiçagem uma grande aliada. Ele afirmava:

Foi pela mestiçagem, como pela ação disciplinadora desses homens de têmpera rija e de caráter varonil, autoritários e sensuais, arrogantes e dissipadores, que se abraçaram as três raças, fundidas na guerra, acamaradadas pelo fogo, como antes o haviam sido pelo trabalho, na comunhão de uma pátria mais estreitada pelo perigo comum do invasor flamengo (Azevedo, 1958, p. 22).

O desenvolvimento da vida política brasileira deu-se em razão tanto de fatores objetivos (situados no âmbito da propriedade da terra, da riqueza, do trabalho escravo, das atividades administrativas e mercadoras) quanto em razão dos elementos subjetivos que iam constituindo e dilatando os valores, as crenças e os sentimentos comuns. As mentalidades autoritárias, as obedientes e as resignadas - as quais foram-se multiplicando ao atingir mais e mais indivíduos e grupos sociais - ajudaram a petrificar, tão fortemente, o padrão de domínio patriarcal que este conseguiu sobreviver, de alguma forma, por seus resíduos $^{4}$ dentro da república brasileira.

Em razão da diversidade populacional e cultural seria de supor que não haveria possibilidade de formação, no território brasileiro, de uma consciência comum que servisse como alinhavo, nos primeiros séculos, de um sentimento de pertencimento e de origem que abarcasse a todos indistintamente. No entanto, Fernando de Azevedo mostrava que, mesmo nessas condições, teria havido, tanto no litoral quanto no sertão, um crescente processo de reconhecimento mútuo que, se num primeiro momento era somente uma consciência gregária, num segundo, favoreceu o surgimento, muito mais tarde, da idéia de pátria e de nação.

A constituição dessa mentalidade comum de origem e de pertencimento a um território deu-se tanto pelos confrontos entre as três raças principais que se debateram durante todo o período da civilização do açúcar quanto por um mestiçamento que, segundo Fernando de Azevedo, equilibrava, nos moldes discutidos por Freyre, os antagonismos que brotavam desses em- bates. Essa relação de acirramento e de atenuamento de reações opostas entre os grupos formadores do país estiveram na base da vida política brasileira. Em Canaviais e engenhos na política do Brasil, ele afirmava que isso esteve presente nos mecanismos que acionaram as próprias instituições políticas. Individualismo, descentralização e tendência oligárquica seriam características dos engenhos que adentraram as cidades com toda força a partir do século XVIII. O meio urbano dava, então, vazão a uma forma de organização política que, ao mesmo tempo, quebrava e reproduzia os elementos oriundos da civilização rural.

A expansão da cultura da cana que propiciou uma ampla descentralização do poder colonial teria sido um fator decisivo no processo de evolução política do país. Formam-se núcleos agrários que desenvolvem uma política local e indiferente à política nacional. Ao passo que Fernando de Azevedo via nessa autonomia um elemento positivo, Oliveira Vianna assinalava que vinham daí todas as dificuldades de constituição de uma ordem pública no país. Para este último, a autoridade nominal que floresceu nessas condições emperrou as mudanças exógenas, ou seja, aquelas que tinham que ser preparadas e executadas pelo Estado (Vianna, 1982a).

Uma diferença essencial entre esses dois intérpretes do Brasil mencionados no parágrafo anterior é a ênfase dada por eles em formas de mudanças distintas, ou seja, assim como aquele último considerava essencial refletir sobre as (im)possibilidades das mudanças exógenas no Brasil, Fernando de Azevedo procurava, no detalhamento das ações dos diversos grupos, os elementos indicativos de que, ao longo dos séculos, teria havido mudanças endógenas, as quais teriam propiciado a (re) definição de valores, crenças, costumes e, portanto, de mentalidade. Essas mudanças eram tidas, por ele, como essencialmente indicadoras de evolução social.

Observe-se que Fernando de Azevedo concebia a mudança social como um processo contínuo e descontínuo ao mesmo tempo. Há interação e quebra dos elementos definidores da política brasileira. Isso porquê, para ele, teria havido evolução das instituições políticas com a transferência dos faustos patriarcais para as cidades. O progresso dessas últimas impulsionou a formação de novos agentes que durante o século XVIII e XIX estabeleceram formas de balizamento das ações dos grandes senhores rurais. O surgimento de novos atores econômicos, de novas atividades profissionais e de novos interesses (que muitas vezes se aliavam aos antigos, mas não deixavam de trazer à tona novos conflitos e novas formas de ações) iam aos poucos "quebrando (...) os quadros antigos, para facilitar o processo de adaptação e a própria evolução das instituições" (Azevedo, 1958, p. 34). 
Fernando de Azevedo considerava que, nos séculos XVIII e XIX, teriam ocorrido algumas mudanças que favoreceram os primeiros passos rumo à democratização do país. Isso se deu em razão tanto das modificações oriundas de uma nova forma de organização da propriedade, em que as grandes extensões de terras vão lentamente sofrendo golpes que não as suprimiam totalmente, mas criavam uma situação de equilíbrio entre a propriedade mobiliária e a imobiliária, quanto das alterações políticas que ganhavam novos contornos, os quais se iam redefinindo conforme se abria a possibilidade de novos agentes sociais adentrarem no cenário político nacional.

Vivendo da terra uma grande massa da população, estabeleceu-se entre nós desde cedo, como alhures, uma estreita correlação entre a qualidade de proprietário territorial e o gozo dos direitos de cidadão; e, na própria democracia, que mais tarde se instituiu, os proprietários conservaram sempre um direito de fato, e a divisão em classes continuou a ser fundada na fortuna e, especialmente, na propriedade da terra. Se tivermos o cuidado de analisar cada uma das revoluções que se operaram, no país, não podemos deixar de concluir que às mudanças de organização da propriedade corresponderam mudanças análogas na organização política e que toda a revolução política foi ao mesmo tempo uma revolução social, arrastando muitas delas, como a de 1817 e a independência, entre as antigas, e, entre as mais recentes, a mudança de regime em 1889 e a revolução de 1930, uma mudança sensível de proprietários de terras, engenhos ou fazendas (Azevedo, 1958, p. 48).

Enfim, Fernando de Azevedo demonstrava que o exame detalhado do processo social brasileiro possibilitava visualizar os elementos responsáveis por mudanças significativas no decorrer de vários séculos. Em seu entender, o país tinha construído, a seu modo, uma trajetória evolucionária que se distinguia de qualquer outra nação. Seguindo as pistas deixadas por Gabriel Tarde e por Sílvio Romero (1851-1914), ele partilhava da convicção de que as sociedades, dadas as suas especificidades históricas, sociais e culturais, construíam trajetórias distintas em seu processo de diferenciação e evolução social.

Justificando sua filiação ao evolucionismo poligenista, Sílvio Romero afirmava:

[...] O notável escritor Gabriel Tarde, que também é evolucionista, posto que o seja enlarguecendo, não sem razão o conceito de evolução [...] também é sectário das repetições na história, tanto das explicáveis pela hereditariedade, como das que se determinam melhor pela imitação. Ele combatia a idéia de que as sociedades tiveram o mesmo ponto de partida e teriam o mesmo de chegada. Não havia para Tarde, uma mudança unilinear numa mesma ordem e extensão para todas as sociedades (Romero, 1969, p. 572).
Essa perspectiva influenciou os escritos de Fernando de Azevedo quando buscou, no padrão de organização social brasileiro, os traços indicadores de mudança social e política. No modo particular de estabelecimento das primeiras cidades e indústrias da cana, nas maneiras ímpares de expressarem os conflitos entre os novos agentes sociais que emergem dessas condições e na forma singular de organização da estratificação (na civilização do açúcar havia no topo os aristocratas rurais, nas faixas intermediárias os banqueiros e os mercadores que viviam de rendimentos e os mestres de açúcar e os oficiais mecânicos que viviam de salários; o grupo de artesãos era formado pelos ourives, latoeiros e marceneiros, os quais se encontravam numa posição acima daqueles que estavam na base, ou seja, os escravos) - é que Fernando de Azevedo procurava extrair os elementos indicadores de que o país havia seguido, desde o início, um curso evolucionário próprio. Portanto,

encontra-se, em sua obra, uma influência mais acentuada dos pressupostos evolucionistas de Émile Durkheim 'que recusava a tese do esquema unilinear de evolução que seria comum a todas as sociedades' (Cuche, 1999, p. 53; Rezende, 2005, p. 175).

Essa postura não significava, porém, que, para ele, tudo era sinônimo de mudança, pelo contrário o movimento era pontilhado por avanços, recuos, estagnações, possibilidades e dificuldades. Desse modo, ele buscava identificar em meio a inúmeros impedimentos econômicos, políticos e culturais os traços indicadores de que havia, no país, potencialidades de alterações sociais ora mais ora menos substantivas.

Verificava-se, então, que Fernando de Azevedo

foi se desvencilhando das explicações naturalistas e produzindo interpretações que situavam mais e mais os fenômenos sociais num domínio próprio, ou seja, no domínio realidade particularmente social, como sugeria Durkheim (Rezende, 2005, p.175).

\section{As dificuldades de formação de elites democráticas no país}

Fernando de Azevedo insistia que o aparecimento de algumas mentalidades esclarecidas no âmbito da própria elite, no decorrer do século XIX, não culminou em mudanças sociais e políticas substanciais. Isso se devia ao fato de que

nesse estado social e político que se caracterizava pela inexistência de uma sociedade esclarecida e politicamente organizada e de que não podia sair um corpo eleitoral capaz e responsável, as elites, reduzidas em 
número e em qualidade, com algumas figuras de primeira grandeza, eram, como continuaram a ser na república, [...] uma frágil casca de refinamento aplicada sobre os corpos geográficos enormes, ainda elementares ou caóticos; pequenas aristocracias cultivadas, mas cujo suporte humano não é senão um bloco primitivo, amorfo e mal-talhado (Azevedo, 1996, p. 173).

Em $A$ cultura brasileira ele argumentava que havia um emperramento até mesmo dos processos de expansão das elites. Um pequeno grupo dirigente tinha a incumbência de decidir praticamente tudo que era importante em matéria de política no país. Desse modo, estancavase qualquer evolução. E isso se devia exatamente a quê? A uma estrutura social que travava a emergência de novas forças sociais capazes de adentrar a arena política. As forças que aparentemente eram novas não o eram inteiramente, uma vez que elas encontravam-se ligadas ao aristocrata rural. O bacharel contrapunha-se, às vezes, aos grandes proprietários de terras, mas reproduzia um modo de agir que acabava por manter essa lógica da não-expansão dos atores capazes de empoderar-se e, assim, intervir, de fato, nos rumos da política. Fernando de Azevedo insistia, porém, que

a ascensão dos bacharéis e dos letrados, brancos e mulatos, contribuiu certamente para melhor definir a linha de demarcação entre a burguesia das cidades, enriquecidas de novos elementos, e a velha aristocracia territorial (Azevedo, 1958, p. 131).

Nesse processo de mudança que se estabeleceu durante o século XIX, detectavam-se vários complicadores, já que "diversos fatores de ordem econômica e social trabalhavam na mudança da estrutura do país" (Azevedo, 1996, p. 173). Essa dinâmica gerava um amplo corpo administrativo e burocrático nos centros urbanos que, ao mesmo tempo, dava uma nova feição ao padrão de organização social, mas pouco alterava o padrão de domínio vigente. Isso potencializava, no campo político, a dificuldade de gerar uma elite com capacidade de ações e atitudes democráticas.

Em Canaviais e engenhos na vida política do Brasil, ele defendia a tese de que as condições para a formação de uma sociedade democrática poderiam advir das transformações socioeconômicas que obrigariam os indivíduos a se renovar continuamente e, portanto, a abrir espaços por onde fluiriam novos interesses e novos agentes. Nesse caso específico, ele ressaltava que o processo de superação de uma economia arcaica e de desenvolvimento da industrialização poderia ser um fator essencialmente modificador da vida política, porquanto abriria a possibilidade de criação de uma elite econômica e política mais voltada para os interesses nacionais. Em decorrência dessas condições, as novas elites poderiam impor ações potencializadoras de mudanças pela educação, por exemplo.

A implementação de uma educação pública e universal impulsionaria a criação de uma elite democrática. No Brasil, durante a colônia e o império, mesmo com todas as suas deficiências, a educação teria sido um fator de diferenciação social, ao mesmo tempo que ela atenuou o autoritarismo e o gosto pelo mando. Os bacharéis em seu entender eram novos tipos sociais que teriam, de alguma forma, contribuído para a evolução política do país ${ }^{5}$. Se a educação elitista foi capaz de provocar mudanças significativas graças à formação de perspectivas políticas múltiplas, e às vezes, diferenciadas daquelas em vigor entre a aristocracia rural, era evidente que uma educação democrática poderia levar, de fato, a transformações da sociedade como um todo, até mesmo das elites e de seus métodos de administrar o país.

O processo educacional que teria vigorado durante o império e os primeiros anos da república, do qual somente os setores preponderantes participavam, não podia alterar inteiramente a mentalidade oligárquica e autoritária prevalecente. Havia um verniz de erudição e de conhecimento literário que não barrava as atitudes personalistas e não-democráticas das elites. Estas revelavam a permanência de um espírito autoritário que contaminou, no decorrer dos séculos XIX e XX, a vida partidária e a administração pública em geral. Enfim, os homens e as instituições iam reproduzindo sucessivamente as práticas oligárquicas.

A organização e o funcionamento dos partidos, no Brasil, a resistência que opuseram e continuam a opor às transformações de estrutura e à sua própria renovação, e a força com que se reagruparam, para ressurgirem com a mesma mentalidade e as mesmas técnicas, depois das grandes crises, denunciam no personalismo uma das molas reais do mecanismo da vida política (Azevedo, 1958, p. 101).

O não-investimento em uma política educacional que atingisse o maior número possível de brasileiros favorecia uma baixa educação política potencializadora da patronagem, do personalismo e do oligarquismo que podiam ser sintetizados na indistinção entre o público e o privado. Os bacharéis, por exemplo, no decorrer do século XIX estavam imbuídos de novas

5 Há uma enorme controvérsia entre os intérpretes do Brasil sobre o papel dos bacharéis na política brasileira durante o século XIX. As ações políticas destes últimos significaram ou não avanços no país? Alberto Torres, Olavo Bilac, Monteiro Lobato e Manoel Bomfim argumentavam que não. Gilberto Freyre e Fernando de Azevedo consideravam, cada um a seu modo, que os bacharéis tinham tido papel importante na evolução política do país. Este segundo afirmava: "Bacharéis, ainda provenientes da casa-grande, mas incorporados ao organismo urbano, acabavam políticos e freqüentemente revolucionários" (Azevedo, 1958, p. 131). 
idéias, de novos conhecimentos e de novos ideais políticos que se mesclavam ao espírito oligárquico vigente. O processo de renovação das elites teria sido, então, tortuoso, já que as crises, as guerras (cabanagem, balaiada, farrapos e sabinada), as oscilações econômicas, a ascensão da burguesia urbana e dos bacharéis, a mestiçagem e a emergência de idéias liberais e democráticas produziam uma evolução social inibida pelos segmentos da aristocracia rural desejosos da manutenção do status quo.

Fernando de Azevedo atribuía à renovação das idéias um papel-chave na construção da mudança social. Ele demonstrava que no século XIX alguns indivíduos oriundos da aristocracia rural e da burguesia urbana romperam com as mentalidades conservadoras e deram "impulso ao movimento de progresso, mediante a formação de correntes de reforma e de renovação" (Azevedo, 1958, p. 134) calcadas em idéias de liberdade que pareciam soltas no ar uma vez que não havia qualquer suporte social para as mesmas. No entanto, o ideário de liberdade que ganhava corpo naquele momento pelos movimentos de 1789 (inconfidência mineira), de 1817 (insurreição pernambucana) e de 1824 (Confederação do Equador) teria tido um papel importante para revelar que existia uma tendência para a renovação e para a mudança. Esta, evidentemente, convivia e se debatia com a tendência, que se espraiava república adentro, de conservantismo exacerbado que se expressava nas ações não só da aristocracia rural, mas também da burguesia urbana.

O conservadorismo, a partir da república, ficava expresso no desprezo que as elites urbanas e rurais demonstravam pela educação popular e pela inteligência do povo em geral. Isso não significava, porém, que havia uma condenação natural dessa elite à não-mudança. Ele recusava todo tipo de fatalismo e, portanto, advogava que até mesmo esta última poderia ser modificada de modo a voltar-se para os interesses coletivos. Ou seja, o traçado da vida social vai-se constituindo de ações diversas e modificáveis. A educação, por exemplo, era tomada, por ele, como um processo capaz de alterar tanto a mentalidade individualista das elites brasileiras quanto os conteúdos políticos de suas ações. Não havia, assim, uma condenação natural ao não-progresso e à não-evolução social em razão de uma mentalidade potencializadora de um sentimento não-público por parte das elites. Em último caso, estas seriam impelidas a modificar-se, dada a irreversibilidade das transformações econômicas, sociais e culturais provocadas pelo desenvolvimento da industrialização, da urbanização e da ciência.

Fernando de Azevedo tanto em Canaviais e engenhos na vida política do Brasil quanto em $A$ cultura brasileira dedicou inúmeras páginas para atestar que as dificuldades de mudanças, que estavam relacionadas ao caráter oligárquico e personalista das elites, poderiam ser superadas mediante a modernização das relações econômi- cas que impulsionariam o desenvolvimento de políticas educacionais, trabalhistas e sociais e o surgimento de embates políticos em razão da prevalência de interesses diversos, os quais suscitariam modificações profundas no modo de ser e de agir das elites brasileiras.

No artigo $A$ evolução das elites políticas no Brasil contemporâneo e, particularmente, em São Paulo, escrito em 1960, ele revia, no entanto, essa sua posição. As elites, de fato, ter-se-iam renovado a partir de 1930, mas teriam mantido seu caráter oligárquico. A heterogeneidade social advinda de uma sociedade que se industrializou não levou à eliminação de suas mentalidades personalistas voltadas para ações políticas que desprezavam os interesses coletivos e/ou nacionais. Enfim, as elites teriam apresentado uma trajetória particularmente asseguradora de suas posições e de seus métodos de fazer política (Azevedo, 1962, p. 233).

Fernando de Azevedo chegava à conclusão de que o processo de urbanização e de industrialização não teria trazido os resultados esperados no âmbito da política.

Deste modo, a estrutura sócio-política, em lugar de abalada por estes dois processos mais recentes, bastante diversos dos anteriores, foi fortalecida por mudanças por eles determinadas. A movimentação interna de indivíduos e grupos, mesmo quando estes se multiplicavam, e quando a quantidade de camadas sociais aumentava, conservava sempre hierarquia semelhante; podia aumentar a quantidade de indivíduos que as compunham, porém a escalação era a mesma e as camadas superiores conservavam o poder econômico e o mando político. A multiplicação das camadas intermediárias, observada nos tempos atuais, fazia avultarem os níveis entre o mais baixo e o mais alto, agindo como um fator suavizante na mobilidade descendente das famílias de condição, e oferecendo maior número de degraus para a ascensão das inferiores (Queiroz, 1994, p. 61-2).

Não se deve deixar de mencionar que já na década de 1940, em algumas passagens do livro $A$ cultura brasileira, ele parecia duvidar da substancialidade das mudanças políticas que a industrialização e a urbanização poderiam trazer. Aquela primeira deveria ser, no seu entender, instrumento de unidade nacional para a democratização, "mas o movimento democrático parecia estar na razão inversa do desenvolvimento da grande indústria" (Azevedo, 1996, p. 182-3).

Havia, contudo, elementos de diferenciação social fora da vida política a partir de 1930, o que podia ser observado mediante a análise da vida econômica que apontava para a emergência de elementos impulsionadores da evolução. No entanto, na vida política, em 1937, ocorriam recuos que atingiam inteiramente os ideais democráticos. O retorno da centralização, a dissolução do parlamento e dos partidos políticos eram indicadores de retrocessos que tendiam a se repetir continuamente na vida política brasileira. 
A diferença fundamental entre as discussões empreendidas, por ele, em $A$ cultura brasileira e as realizadas em $A$ cidade e o campo na civilização industrial $e$ outros ensaios, estava em sua tentativa, naquele primeiro livro, de extrair traços de positividade de um processo político que mesmo não sendo democrático, traria, em seu entendimento, resultados benéficos se conseguisse combater a mentalidade política patriarcal ainda vigente no país. O período pós-1937 era, segundo ele, somente uma fase que seria superada tão logo se conseguisse a unificação nacional.

É uma fase nova que se inaugura e em que o princípio da ordem, da unidade e da defesa nacional se impõe novamente, com toda a sua força, como no período da regência; e a sociedade agora centralizada [...] evolui para o igualitarismo, impelida por grandes reformas sociais e econômicas, enquanto se realiza um dos maiores esforços de unificação e de reconstrução, num espírito e em bases eminentemente nacionais (Azevedo, 1996, p. 183).

Esse seu raciocínio era evidentemente contraditório por considerar a ditadura de Vargas um momento necessário para a criação das condições de efetivação da democracia no Brasil. No artigo A evolução das elites políticas no Brasil contemporâneo e, particularmente, em São Paulo, ele não endossava mais esse tipo de tese, o que não significa, porém, que não haja outras contradições nesse último texto. Ao utilizar a teoria da circulação das elites de Pareto, que supunha que toda elite tinha tendência para a oligarquia e não para a democracia, vinham à tona inúmeros problemas, já que a crítica de Fernando de Azevedo não era à sociedade de massa nos moldes do sociólogo italiano, mas, sim, à própria elite brasileira que não abria espaços para que novos agentes sociais tivessem, de fato, um papel relevante no processo de renovação da política brasileira. Se para ele as elites poderiam tornar-se democráticas, para Pareto, isso não passava de uma utopia.

Analisando o que ocorria num país essencialmente agrário que, em 1960, entrava na era da industrialização, o que Fernando de Azevedo encontrou não foi uma elevação das massas, e sim, o aparecimento de novas elites que, para se apoiarem nestas, se voltaram para a 'competição desenfreada', por meio de partidos 'sem programa e sem idéias, retalhados por suas dissensões internas e dispostos, para se facilitar o acesso ao poder, a todas as colisões e às mais disparatadas alianças' (Azevedo, 1962, p. 240). Nesse desenvolvimento político, não eram as massas que tomavam o poder; elas passavam a constituir 'poderoso instrumento de dominação' nas mãos de grupos políticos antigos e novos, que se valiam de quaisquer meios para se manterem no poder uns, e outros para deste se apoderarem" (Queiroz, 1994, p. 64-5).

\section{A educação como fator de criação de uma elite democrática}

Segundo Antônio Cândido, Fernando de Azevedo lidava com a educação

como parte orgânica da sociedade e da cultura, capaz de servir de ponto de apoio para interpretá-las de maneira mais profunda. Este ponto de vista era original e radicava numa concepção, não pedagógica, mas sociológica, certamente inspirada na origem pela obra de Émile Durkheim (Candido, 1994, p. 13).

Assim, pode-se dizer que

De Durkheim ele extraía a tese de que a educação deveria promover uma socialização capaz de sobrepor a natureza social à natureza individual (Azevedo, 1958a, p.17). A criação do homem nacional cujos interesses coletivos deveriam estar acima dos interesses particulares se constituía o eixo central do Manifesto dos Pioneiros da Educação Nova, de 1932, de que Fernando de Azevedo foi redator (Rezende, 2003, p. 74-5).

O país possuía, conforme demonstrava Fernando de Azevedo em seus vários escritos, uma elite que não havia demonstrado ao longo da história do Brasil qualquer sentimento público, qualquer interesse nacional. Responsável, a seu ver, pela implementação de projetos de mudança social, ela precisava ser, então, educada, instruída, na arte da valorização do interesse coletivo e/ou nacional, da apreciação do homem e de tudo que o tornasse capaz de desenvolver a inspiração social, o idealismo e o apreço aos valores democráticos (Azevedo, 1996; 1958a; 1958b).

A escola deveria nortear-se, segundo Fernando de Azevedo, pelos princípios de liberdade, de igualdade e de cooperação que ganharam contornos nítidos na sociedade industrial moderna. [Ele seguia] as teses de Durkheim (1984) acerca da evolução social baseada na industrialização produtora de uma divisão do trabalho (Rezende, 2003, p. 75).

Essa última deveria estar fundada na "complementariedade, cooperação e caráter mutuamente indispensável de funções e ocupações altamente diversificadas" (Sztompka, 1998, p. 187).

Fernando de Azevedo insistia que "a reforma proposta no Manifesto dos Pioneiros da Educação Nova (Penna, 1987, p. 183-201), de 1932, pretendia implementar no Brasil as condições para o florescimento de uma civilização urbano-industrial que possibilitasse o aprimoramento daqueles três princípios [liberdade, igualdade e cooperação] embasadores da diferenciação progressiva (Azevedo, 1956, p. 71; Rezende, 2003, p. 75). 
Ele atribuía à educação um papel essencial na construção de uma mentalidade democrática na população como um todo. Urgia transformar a todos e a própria elite, visto que ela estaria incumbida de dirigir, administrar e conduzir a sociedade brasileira a patamares mais igualitários do ponto de vista social, econômico e político. O processo de reconstrução da paisagem social passava pela criação de um sistema nacional de educação, o que exigia grandes esforços dos governantes, dos intelectuais em geral e dos humanistas em particular, uma vez que não havia, no país, qualquer pensamento coletivo e/ou unidade de interesse em torno da consolidação de um ensino público capaz de desmantelar a cultura antidemocrática que vigia no país.

Nesse regime de educação doméstica e escolar, próprio para fabricar uma cultura antidemocrática, de privilegiados, a distância social entre os adultos e as crianças, o rigor da autoridade, a ausência da colaboração da mulher, a grande diferença de educação dos dois sexos e o predomínio quase que absoluto das atividades puramente intelectuais, sobre as de base manual e mecânica, mostram em que influiu na evolução de nosso tipo educacional a civilização baseada na escravidão (Azevedo, 1996, p. 560).

Eram profundas as raízes da sucessiva dificuldade de sedimentação, em todos os segmentos sociais, de uma mentalidade receptiva aos valores democratizantes. Fazia-se, assim, necessário percorrer a história da formação, no país, de um ambiente social (econômico, político e cultural) que barrou, intermitentemente, progressos no campo da educação pública, a qual era tomada, por ele, como responsável pelo rompimento de uma prática social e política reprodutora da supremacia da esfera privada sobre a esfera pública.

Durante a colônia, após a independência e mesmo depois de 1889, a educação no Brasil não tem conseguido formar homens preparados "para resolver os grandes problemas técnicos e econômicos do país" (Azevedo, 1996, p. 568). Dessa forma, não era somente uma questão de mentalidade privatista, antidemocrática, mas também de despreparo para ler corretamente os problemas que aflingiam a nação. Por que uma economia arcaica prolongou-se república adentro? Uma das razões advinha dessa dificuldade de os setores preponderantes entenderem o significado da própria necessidade de industrializar o país.

A evolução social do país era barrada por motivos econômicos e políticos que se ligavam intimamente. Uma elite essencialmente antidemocrática se apavorava com a possibilidade de a indústria levar a mudanças abruptas e incontroláveis. Ela preferia apostar no arcaísmo agrário. Na segunda metade do século XIX, essas apostas se traduziam nas ações acanhadas no campo educacional. O ensino primário encontrava-se em situação precária, a cargo das províncias. O ensino técnico era algo descolado inteiramente das condições vigentes em que a indústria e o comércio capengariam ainda por anos a fio.

Tinha-se, então, uma ordem econômica e política que impulsionava a sua elite a um tratamento muito específico em relação à educação pública como um todo. Entre os setores preponderantes graçava a indiferença e/ou um suposto interesse pelas letras e pelas atividades intelectuais (D. Pedro II era exemplo disso) que não se traduziam em uma política educacional extensiva para a todos os brasileiros. A formação de ideais democráticos somente seria possível pela instalação de uma instrução pública que atingisse a todos indistintamente, ou seja, cortasse horizontal e verticalmente a sociedade como um todo.

Desde os seus primórdios a sociedade brasileira parecia estar, então, sem qualquer saída. $\mathrm{O}$ ambiente social favorecia o desenvolvimento de uma elite que considerava a educação como algo direcionado a ela particularmente e, ainda assim, somente como um adorno, uma ilustração e uma prova de exuberância. Em realidade, nem para ela a educação tinha o efeito que deveria ter: o de capacitá-la a construir uma nação e de resolver os problemas que esse processo impunha.

Se a educação possuía esse significado de aquisição de um conhecimento abstrato, literário e ilustrativo com o objetivo de valorizar os seus portadores, evidentemente, que ela não poderia ter, no entendimento dessa elite, qualquer sentido quando pensada em termos de expansão para todos os grupos sociais. Os não-membros da elite não tinham, segundo a lógica desse raciocínio, porque receber qualquer conhecimento ilustrativo, uma vez que eles não necessitavam de tal adorno.

Para Fernando de Azevedo, essa mentalidade da elite a respeito da educação não poderia ser mudada enquanto prevalecesse uma ordem econômica arcaica. Portanto, a industrialização e a urbanização seriam os fatores impulsionadores de mudanças no modo dos setores preponderantes conceberem qual era o real significado da educação pública de qualidade universal para todos os membros da sociedade. Não haveria, então, possibilidade de evolução social sem uma mudança econômica e cultural. A introdução daquela primeira imporia, em razão da própria divisão do trabalho que se instalaria, mudanças educacionais que atuariam, durante longos anos, como modificadoras das mentalidades não-valorizadoras dos interesses coletivos. O caminho para a democracia abrir-se-ia, então, por causa da emergência de ações políticas voltadas para a criação de novas instituições.

A mudança política oriunda da proclamação da república não fora suficiente para a implementação de instituições democráticas. A industrialização e a urbanização que implicariam alterações econômica e social poderiam, então, oferecer as condições para que se 
efetivassem ações políticas que fossem desmantelando aos poucos as resistências das elites às inovações no campo econômico, político e cultural.

Do ponto de vista cultural e pedagógico, a república foi uma revolução que abortou e que, contentando-se com a mudança de regime, não teve o pensamento ou a decisão de realizar uma transformação radical no sistema de ensino, para provocar uma renovação intelectual das elites culturais e políticas, necessárias às novas instituições democráticas (Azevedo, 1996, p. 618).

No capítulo Elites e participação, da obra Fernando de Azevedo: educação e transformação (Azevedo, 1958c, p. 141), Maria Luíza Penna afirma:

Uma modificação na constituição do Estado deveria ter por objetivo, segundo a ótica azevediana, o fortalecimento das instituições democráticas, de fragilíssima tradição no Brasil. Para a construção dessa democracia nova, no sempre desejado processo nacional, dois fatores são considerados fundamentais, aspectos complementares de uma política racional de educação: formação das elites e educação popular. Esta última, alicerçada na escola única, universal e gratuita, na escola-comunidade e na escola do trabalho, deveria despertar no povo 'a consciência de suas necessidades e orientar a sua vontade na direção das necessidades sentidas' (Penna, 1987, p. 46).

Entre as inúmeras inovações que poderiam emergir com a industrialização e a urbanização, Fernando de Azevedo se concentrava quase que exclusivamente nas mudanças educacionais que deveriam advir, especialmente, de um plano de ensino - por parte dos dirigentes - que visasse atingir tanto as camadas populares quanto as elites. Nas primeiras décadas do século XX, mesmo com um processo de industrialização ainda incipiente que havia iniciado por volta de 1885 , as reformas no campo educacional teriam permanecido refém das forças reacionárias e conservadoras. Até a década de 1920 não teria sido implementada qualquer política educacional, de fato, inovadora.

Fernando de Azevedo destacava, no entanto, os empecilhos e as dificuldades de implementação de mudanças sociais substantivas.

O entusiasmo de Azevedo pela construção de uma nação brasileira livre, plural, educada e generosa com os cidadãos 'indivíduos da república' era temperado pelo diagnóstico realista de uma tradição histórico-cultural de que somos tributários, tradição de benefícios muito duvidosos. Na introdução de As ciências no Brasil (1994), Fernando de Azevedo nos retrata, os brasileiros e o nosso desenvolvimento científico, como reféns da configuração cultural de um passado patriarcal, agrário e pastoril (Bomeny, 1999, p. 234-5).
Elite não-democrática não significava elite inculta. No Brasil, havia-se formado ao longo dos séculos uma elite culta, porém, autoritária e conservadora. Para Fernando de Azevedo

qual seria a natureza das elites no Brasil? Em retrospectiva, o espetáculo é o de uma elite culta (em geral), de formação europeizante, desvinculada das massas, autoritárias, aparentemente desarticulada e romântica, mas sempre pronta a combater reformas que possam desestabilizar, por pouco que seja, seu controle no poder (Penna, 1987, p. 51).

Entretanto, era possível, a seu ver, mudar essa natureza das elites? Sim, era plenamente possível, apesar de uma cultura política desabonadora e calcada no autoritarismo. Em Canaviais e Engenhos na vida política do Brasil, ele demonstrou o quanto o habitus autoritário, conservador e reacionário estava presente na constituição da burguesia urbana. A maneira de ser e de pensar, o estilo da conduta e o modus de ação continuavam, no decorrer do século XX, impregnados tanto de um enorme desprezo pelo povo quanto por uma concepção abstrata de liberdade (Azevedo, 1958; 1996).

Essa situação, afirmava ele nos anos 1940, tendia a se modificar, visto que estaria em curso, desde o início do século XX, com a industrialização, a emergência de um jogo político que tendia a mudar a natureza das elites. A burguesia urbana, mesmo sem o desejar, estava imersa em um contínuo embate com outras forças sociais que despontavam nos centros urbanos, ou seja, os operários e os setores médios. A burguesia poderia sair modificada, ao mesmo tempo que tivesse de enfrentar um conjunto de forças plurais. Sua natureza poderia ter-se tornado democrática no âmbito desse embate, o que, de fato, não ocorreu, conforme ele demonstrou alguns anos depois, no artigo A evolução das elites políticas no Brasil contemporâneo e, particularmente, em São Paulo, conforme foi discutido no final do item anterior.

Enfim, na década de 1960, tanto no artigo $A$ evolução das elites políticas no Brasil contemporâneo e, particularmente, em São Paulo quanto no Manifesto dos intelectuais, de 1965, em repúdio ao golpe militar, Fernando de Azevedo demonstrava que não se vislumbravam quaisquer mudanças na natureza das elites brasileiras ao mesmo tempo que elas apoiavam, naquele momento, um regime sectário e intolerante, portanto, contrário às instituições democráticas, às diferenças políticas e à própria liberdade (Azevedo apud Penna, 1987, p. 202-203).

Segundo Fernando de Azevedo, o processo de industrialização e de urbanização não teria levado a uma mudança de mentalidade das elites, conforme ele havia suposto nas décadas de 1930 e 1940 . No período pós-64, isso teria ficado evidente na predisposição dos setores preponderantes em apoiar um regime que visava eliminar todas as forças plurais que tinham emer- 
gido entre 1930 e 1964. Ou melhor, os embates sociais e políticos oriundos de uma sociedade que se diversificava não teriam sido escola de formação democrática para as elites dirigentes. Elas pareciam refratárias a quaisquer mudanças tanto que não hesitaram em apoiar, a partir de 1964, a intransigência de um regime que fechava todos os canais de ação política para diversos segmentos sociais.

\section{Conclusão}

A pergunta implícita nos textos de Fernando de Azevedo que tratam das mudanças políticas é a seguinte: havia possibilidade de passagem do patriarcalismo para a democracia? Ou aquele primeiro teria desenvolvido e sedimentado um conjunto de relações irremediavelmente autoritárias? Essas relações teriam comprometido definitivamente o processo de democratização do país? Ele trabalhava com uma idéia interessante para mostrar o grau de dificuldade que o país vinha enfrentando, no campo político, desde o império. Ou seja, a organização política que vai tomando forma com base na independência e, mais tarde, da república era praticamente um decalque do padrão de domínio vigente nos séculos anteriores.

No Império - diante do poder patriarcal e de suas ações refutadoras da expansão da esfera pública, portanto, da democracia - o governo de Pedro II agia de que maneira? Segundo Fernando de Azevedo, ele tentava conciliar o autoritarismo do patriarca com o poder central. Nos moldes de Oliveira Vianna ele argumentava que isso teria servido para macular inteiramente o desenvolvimento de um poder público capaz de solapar definitivamente o poderio localista, familista e personalista (Vianna, 1982; 1982a).

A reflexão de Fernando de Azevedo acerca das (im)possibilidades de que ocorressem mudanças políticas para a democratização do país, assentava-se, expressivamente, em sua perspectiva de que há uma mescla de idéias e de costumes que podem tanto permanecer quase que inalterados diante de modificações políticas expressivas (a independência e a república, por exemplo) quanto alterar-se levemente. Assim, o grande desafio é entender até que ponto as modificações de formas sociais podem levar ou não, paralelamente, a mudanças nos conteúdos sociais.

O próprio modo de os indivíduos perceberem a vida política no decorrer do império e da república mostrava que conviviam, no âmbito da própria elite, mentalidades renovadas e mentalidades empedernidas. Ressalte-se que o exame das ações e das condutas de parte expressiva dos setores preponderantes, após a independência, revelava a prevalência de uma cultura personalista do poder, nos feitios que vigoravam no período colonial.

\section{Referências}

AZEVEDO, Fernando de. Canaviais e engenhos na vida política do Brasil. São Paulo: Melhoramentos, 1958.(1 Edição 1948).

Princípios de Sociologia. São Paulo: Melhoramentos, 1956. (1 E dição 1935).

Novos caminhos e novos fins. São Paulo: Melhoramentos, 1958a. (1º Edição 1931).

Sociologia educacional. São Paulo: Melhora-

mentos, 1958b. (1º Edição 1940).

A educação e seus problemas. São Paulo: Me-

lhoramentos, 1958c. (1º Edição 1952).

- A cultura brasileira. Rio de Janeiro/Brasí-

lia: UFRJ/UNB, 1996. (1º Edição 1943).

. As ciências no Brasil. Rio de Janeiro: Editora da UFRJ, 1994. (1º Edição 1956).

A cidade e o campo na civilização industrial e outros ensaios. São Paulo: Melhoramentos, 1962.

BOMENY, Helena. "Fernando de Azevedo: sociologia, educação e a ciência brasileira". In: MAIO, Marcos Chor C.; VILLAS BÔAS, Gláucia (Orgs.). Ideais de modernidade e sociologia no Brasil. Porto Alegre: UFRGS, 1999.

BOMFIM, Manoel. O Brasil nação: realidade da soberania brasileira. Rio de Janeiro: Francisco Alves, 1931.

CÂNDIDO, Antônio. Um reformador. Revista do Instituto de Estudos Brasileiros. São Paulo, USP, n.37, p. 11-17, 1994.

CUCHE, Denys. A noção de cultura nas ciências sociais. Bauru: Edusc, 1999.

CUNHA, Euclydes da. Os sertões. Rio de Janeiro: Francisco Alves, 1995.

. Obra completa. Rio de Janeiro: Aguillar, 1996.

DURKHEIM, Emile. A divisão do trabalho social. Lisboa: Presença, 1984.

As formas elementares da vida religiosa. São Paulo: Martins Fontes, 1996.

DURKHEIM, Emile; MAUSS, Marcel. Note sur la notion de civilisation. L'Année Sociologique. Paris, v.12, p. 46-50, 1913.

FREYRE, Gilberto. Casa grande E senzala. Rio de Janeiro: J.Olympio, 1994. . (1961) Sobrados e mucambos. Rio de Janeiro: J. Olympio, 1961.

GOLDTHORPE, John. Herbert Spencer. In: RAISON, Timothy (Org.). Os precursores das ciências sociais. Rio de Janeiro: Zahar, p. 83-91, 1971. 
HOLANDA, Sérgio Buarque de. Raízes do Brasil. Rio de Janeiro: J. Olympio, 1987.

LEVINE, Donald. Visões da tradição sociológica. Rio de Janeiro: Jorge Zahar, 1997.

VIANNA, Francisco José Oliveira. Populações meridionais do Brasil. Brasília: Câmara dos Deputados, 1982. Instituições políticas brasileiras. Brasília: Câmara dos Deputados, 1982a.

PARETO, Vilfredo. Manual de economia política. São Paulo: Nova Cultural , 1988. (Col. Os economistas).

PENNA, Maria Luiza. Fernando de Azevedo: educação e transformação. São Paulo: Perspectiva, 1987.

QUEIROZ, Maria Izaura Pereira. Fernando de Azevedo: o sociólogo. Revista do Instituto de Estudos Brasileiros, n.37, IEB/USP, p.53-69, 1994.

REZENDE, Maria José de. A democracia no Brasil: um confronto entre as principais perspectivas teóricas na primeira metade do século XX. Mediações, Londrina, v.1, n.1, p.29-39, jan.jun, 1996.

A democracia em Gilberto Freyre e Sérgio Bu-

arque de Holanda. São Paulo, Plural, n.3, p.14-48, 1996a.
. Educação e mudança social em Fernando de Azevedo. Acta Scientiarum, Maringá, n.1, p.73-85, 2003.

. Diferenciação, evolução e mudança social em

Fernando de Azevedo. Cronos, Natal, v. 5/6, p. 173-192, 2005.

ROMERO, Sílvio. Obras filosóficas. Rio de Janeiro: J. Olympio, 1969.

SPENCER, Herbert. On Social Evolution. Chicago: Chicago University Press, 1972.

. The Study of Sociology. Ann Arbor: University of Michigan Press, 1961.

Reasons for Dissenting from the Philosophy of $M$.

Comte and Other Essays. Berkeley: Glenessary Press, 1968.

SZTOMPKA, Piort. A sociologia da mudança social. Rio de Janeiro: Civilização brasileira, 1998.

TIMASHEFF, Nicolas. Teoria sociológica. Rio de Janeiro, Zahar, 1965.

VILA NOVA, Sebastião. Sociologias \& Pós-Sociologia em Gilberto Freyre. Recife: Massangana, 1995.

WILLEMS, Emilio. Forma social. In: Dicionário de Sociologia. Porto Alegre: Globo, p. 137, 1977.

\title{
The Difficulties in Constructing a Democratic Society in Brazil: the Extrapolitical Elements in the Analyses of Social Processes in Fernando de Azevedo
}

\begin{abstract}
Fernando de Azevedo's discussions about Brazilian political life since the beginning of the social formation of the country will be privileged in this article. He built up one of the most fertile reflections in the political culture field as he historically rescued the difficulties in establishing a democratic society and, at the same time, made every effort to point out the directions that should be followed in order to achieve it. He contributed to the implementation of the investigations which valued extra-political elements in the analyses of social processes, as well as the sociological context, showing that the substantial changes are only possible when changes in the mentalities which guide them occur.
\end{abstract}

Key words: politics; society; change; culture; differentiation.

Data de recebimento do artigo: 04-04-2008

Data de aprovação do artigo: 24-09-2008 